\title{
DEMOGRAPHIC DETERMINANTS OF LEGAL CONSCIOUSNESS FOR EUTHANASIA LEGALIZATION IN PATIENTS WITH POLYMORBIDITY AND PERMANENTLY DIMINISHED WORK CAPACITY
}

\author{
Paraskeva Mancheva $^{1}$, Albena Kerekovska ${ }^{2}$, Valentina Madjova ${ }^{1}$ \\ ${ }^{1}$ Department of General Medicine and ${ }^{2}$ Department of Social Medicine \\ and Public Health Organization, Medical University of Varna
}

\begin{abstract}
PURPOSE: This study aims at studying the influence of demographic determinants on defining the legal consciousness for euthanasia legalization in patients with polymorbidity and permanently diminished work capacity.

MATERIAL AND METHODS: The study sample includes 305 respondents certified by the General Medical Committee at St. Marina University Hospital of Varna as having polymorbidity and permanently diminished work capacity.

RESULTS: There is a significant effect of respondent's demographic characteristics such as religious and gender, educational level and employment on three main components of legal consciousness - cognitive (legal information), psychological (evaluations, relations, values) and behavioural one (tendency for legally relevant behaviour) concerning euthanasia legalization. These results prove the need of preliminary investigation of the legal consciousness of target social groups prior to execution of legal changes concerning certain socially important issues like euthanasia.
\end{abstract}

Key words: euthanasia, legal consciousness, polymorbidity, permanently diminished work capacity

\section{INTRODUCTION}

The 'for' and 'against' debate in Bulgaria about euthanasia is intransient and deeply rooted in the problems of modern society, the widespread popularization of patient rights $(1,11)$ and the bill drafted in June 2011 moving to legalize it (3). This issue has

\footnotetext{
Address for correspondence:

Paraskeva Mancheva, MD

Department of General Medicine, Faculty of Public Health

Medical University of Varna

55 Marin Drinov Street, 9002 Varna, Bulgaria

e-mail:p_mancheva@abv.bg
}

Received: January 10, 2013

Accepted: March 22, 2013 not been studied relevantly in Bulgaria, especially in its medical and legal aspects, and it requires the application of suitable tools for social and legal research into channeling the public reaction towards a certain legislative initiative, a particular legislative resolution and its result.

Legal consciousness (LC) is a relatively new formal scientific concept. It is the link between the law and actual human behaviour, as it reflects legal reality and the rights and obligations contained in legal norms. The very norms are a 'carrier' of certain LC, both of lawmakers and of society, and this is reflected in the law making process as a synthesis of jus (law) and justum (justice) $(6,15)$.

The search for optimal authenticity in law making research requires that this is carried out amongst 
Demographic determinants of legal consciousness for euthanasia legalization in patients with polymorbidity ...

such groups of society which might turn out to be potential users of the particular legal result. Patients with polymorbidity and permanently diminished work capacity (PP with PDWC) are a contingent of constantly rising significance in Bulgarian society as their number surges upwards and as a result of the unsolved health and social issues and the existence of potential suicidal attempts and a personal decision for euthanasia (5).

The broad understanding of euthanasia defines it as application of both active and passive methods. A narrow debate of the euthanasia phenomenon only includes the actions which lead directly to death and relates to the professional and deontological ethics of the concept that Lisaev reviews as 'the possible law or the moral duty of the physician to speed or cause the death of very and hopelessly ill patients at their own request in order to shorten their suffering, i.e. shortening or ending patient's life by direct medical action or inaction' (4). Human history knows cases of ungrounded widening of euthanasia practices, which inevitably leads to perversion of the humane idea contained within (12).

The discussion of 'pro' and 'contra' euthanasia includes the issue of its legal grounding, whether it should be legalized or not. The greater part of contemporary societies have evolved greatly in their understanding of this major social, philosophical, ethical, medical and legal issue $(2,10,13)$. In the period of dynamic change of the contemporary democratic society, the role of public opinion for the resolving of important social issues is evermore increasing (16). Bulgarian society is beginning to study the opinions and needs of its citizens before resorting to changes in the law.

Exact definition of the term of 'human rights' (11) has changed the content of the euthanasia phenomenon and poses it as a focus for discussion ever so frequently for the following reasons:

* advance of modern medicine and pharmacology which tends to extend life but also leads to an increased use of medical resource;

* improvement of the quality and duration of life and increase of the number of severely and chronically ill patients, and
* changes in the understanding of man and society about life and the right to have one's own command on death.

* LC of the individual and society is the link between law and actual human behaviour as it reflects legal reality, legal norms, rights and obligations. Within the mechanism of formation of legally relevant behaviour, each of the citizens' LC plays a certain role (7) with its three main components: cognitive (legal information), psychological (evaluations, relations, values) and behavioural one (tendency for legally relevant behaviour).

* LC is defined as a sphere of the social, group or individual consciousness that reflects legal reality in the form of legal knowledge, evaluation approaches to law and its practical application, legal tendencies and values regulating behaviour in juridically important situations (8). The truthful reflection of legal reality requires the research on law making to be carried out amongst such society groups which might eventually turn out to be the users of this particular legal result. In this respect, PP with PDWC are a suitable research material for LC about euthanasia as their number surges upwards and as a result of the unsolved health and social issues and the existence of potential suicidal attempts and a personal decision for euthanasia $(9,14)$.

This study aims at studying the influence of demographic determinants for LC definition concerning euthanasia legalization in PP with PDWC.

\section{MATERIAL AND METHODS}

The study was carried out during the period between October 2011 and November 2011 in Varna Region among 305 PP with PDWC living in Varna and certified by the General Medical Committee at the St. Marina University Hospital of Varna. The sample was taken out from the General Medical Committee's Register.

Direct individual and group questionnaire developed by the Department of General Medicine, Medical University of Varna was used. The confidence interval (CI) was $14,83 \%$, the representative error - $3,98 \%$, the response rate $-97,81 \%$. Average age of 
Paraskeva Mancheva, Albena Kerekovska, Valentina Madjova

the interviewed patients was $60 \pm 10$ years, 161 of them were men and 144 women. Their demographic characteristics were presented in Table 1.

Data analysis was performed by means of SPSS statistical package v. 15.0 for Windows and applying correlation analysis and $\chi^{2}$-analysis. Statistical significance was accepted if $\mathrm{p}<0,05$.

\section{RESULTS}

The results show an insignificant dependence of patients' informativeness about euthanasia on their age group. The analysis demonstrates the attitude towards active euthanasia and demonstrates
The analysis of patients' readiness to vote 'for' legalization of active euthanasia in Bulgaria shows greater values in women to debate the issue $\left(\chi^{2}=13,04\right.$; $\mathrm{p}<0,01)$. The women are more prone to express their vote about legalization of euthanasia ( $35,2 \%$ 'for' and $47,2 \%$ 'against') while men tend to vote negatively (41\%), or remain neutral with an answer 'I don't know' (32,3\%) (Fig. 1).

The females are more prone to refusing lifesupport treatment if they suffer from an incurable ailment leading to a painful and fatal outcome $(52,7 \%)$, while $40 \%$ of the males would not refuse $\left(\chi^{2}=11,64 ; p<0,05 ; r=-0,14 ; p<0,05\right)$ (Fig. 1).

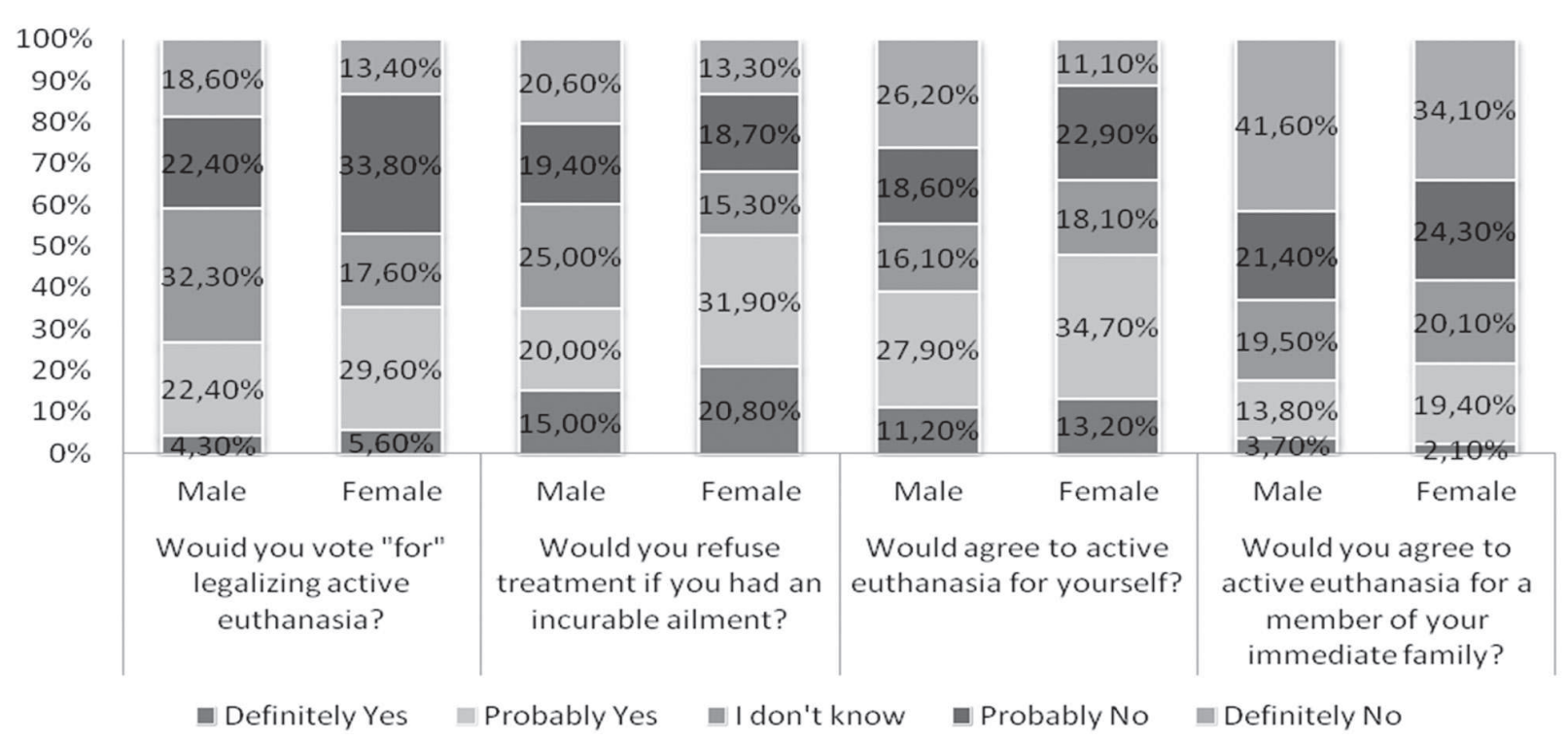

Fig. 1. Relationship between gender and behaviour to euthanasia

approval in patients under the age of 40 in 63,3\% of the cases. The older age groups approve such a possibility, too, however, they think the decision can be made by their closest relatives, too $\left(\chi^{2}=9,65\right.$; $\mathrm{p}<0,05 ; \mathrm{r}=-0,14 ; \mathrm{p}<0,05)$. The patients from the age group between 41 and 60 years (47,15\%) and over 60 years $(39,7 \%)$ are the most prone to accepting active euthanasia while those aged under 40 years are of the opposite opinion $(63,6 \%)$.

There is a significant dependence of the amount of information about euthanasia on gender $\left(\chi^{2}=4,34\right.$; $\mathrm{p}<0,05)$. Females are better informed than males about the essence of euthanasia (64,2\% versus $49,8 \%$, respectively), which shows a greater interest in this group in the issue at hand $(\mathrm{r}=-0,12 ; \mathrm{p}<0,05)$.
Female respondents present with higher readiness to agree to active euthanasia for themselves $(47,9 \%)$ than males $(39,1 \%)\left(\chi^{2}=11,17 ; \mathrm{p}<0,05 ; \mathrm{r}=-0.14\right.$; $\mathrm{p}<0,05)$ (Fig. 1).

Education is another crucial factor for determining the level of informativeness about euthanasia of PP with PDWC. The respondents with the lowest educational level are the least informed about the essence of euthanasia (58,9\%), whereas the most informed are those with college $(89,6 \%)$ and higher educational level $(81,9 \%)(\mathrm{r}=-0,15 ; \mathrm{p}<0,01)$.

The respondents with primary $(40 \%)$ and secondary $(46,7 \%)$ education are the least informed about the legal norms concerning euthanasia in Bulgaria, while those with college $(68,7 \%)$ and 
higher $(66,6 \%)$ education show higher levels of informativeness $(r=-0,21 ; p<0,001)$.

Concerning the influence of the factor 'occupation' on LC for euthanasia there is a significant difference with respect to the informativeness of respondents only. The group of the retirees is less informed about the essence and the legal norms of euthanasia than that of the unemployed and the
Adventists are the best informed group (87,5\%) followed by the Protestants (75\%) and Methodists $(61,9 \%) \quad\left(\chi^{2}=11,07 ; p<0,05\right)$ while Muslims are the least informed (39,3\%).

The analysis of the relationship between religious affiliation and approval of active euthanasia establishes that a large number of the Adventists do not approve of active euthanasia $(62,6 \%)$ while

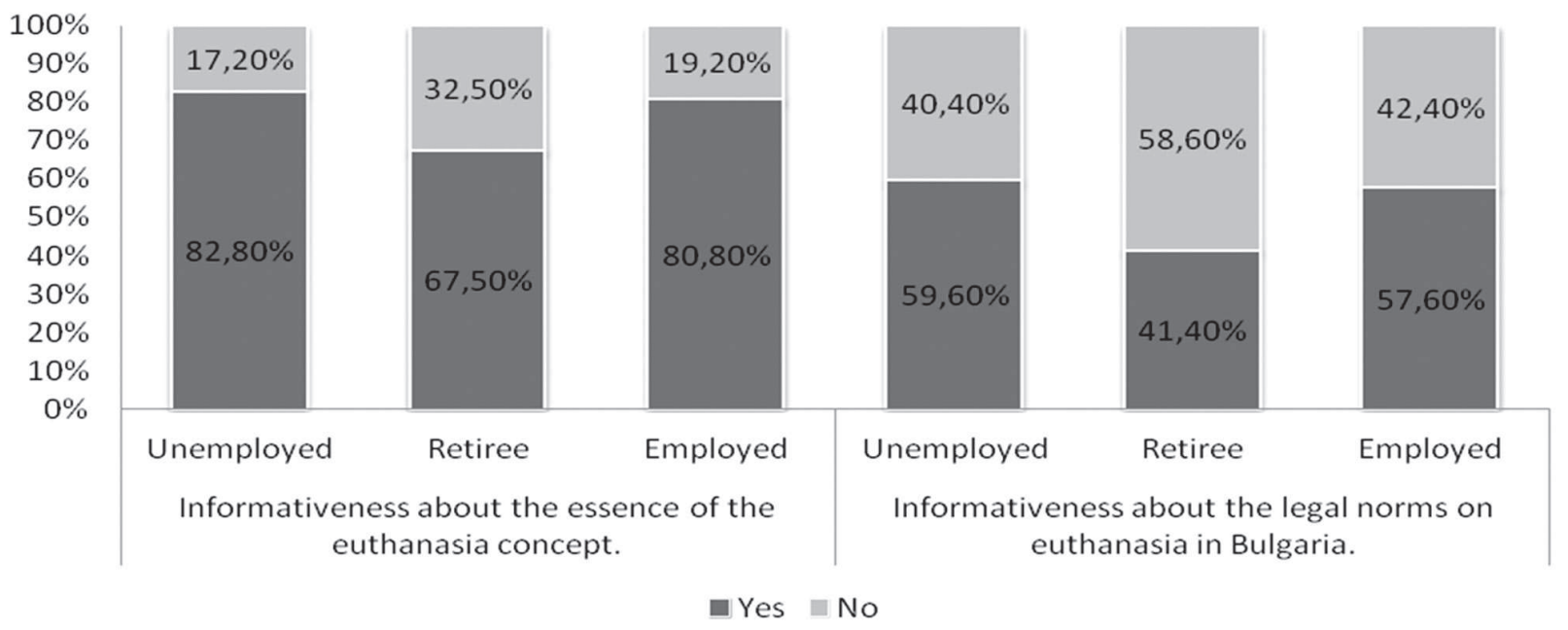

Fig. 2. Relationship between occupation and informativeness about euthanasia

employed respondents (Fig. 2).

There are no considerable differences between the different religions in terms of the informativeness about euthanasia. Concerning the legal norms,
Protestants tend to accept it as a possible way out of an impossible situation $\left(\chi^{2}=0,84 ; p<0,05\right)$. With the other religions, responses vary in different degree as

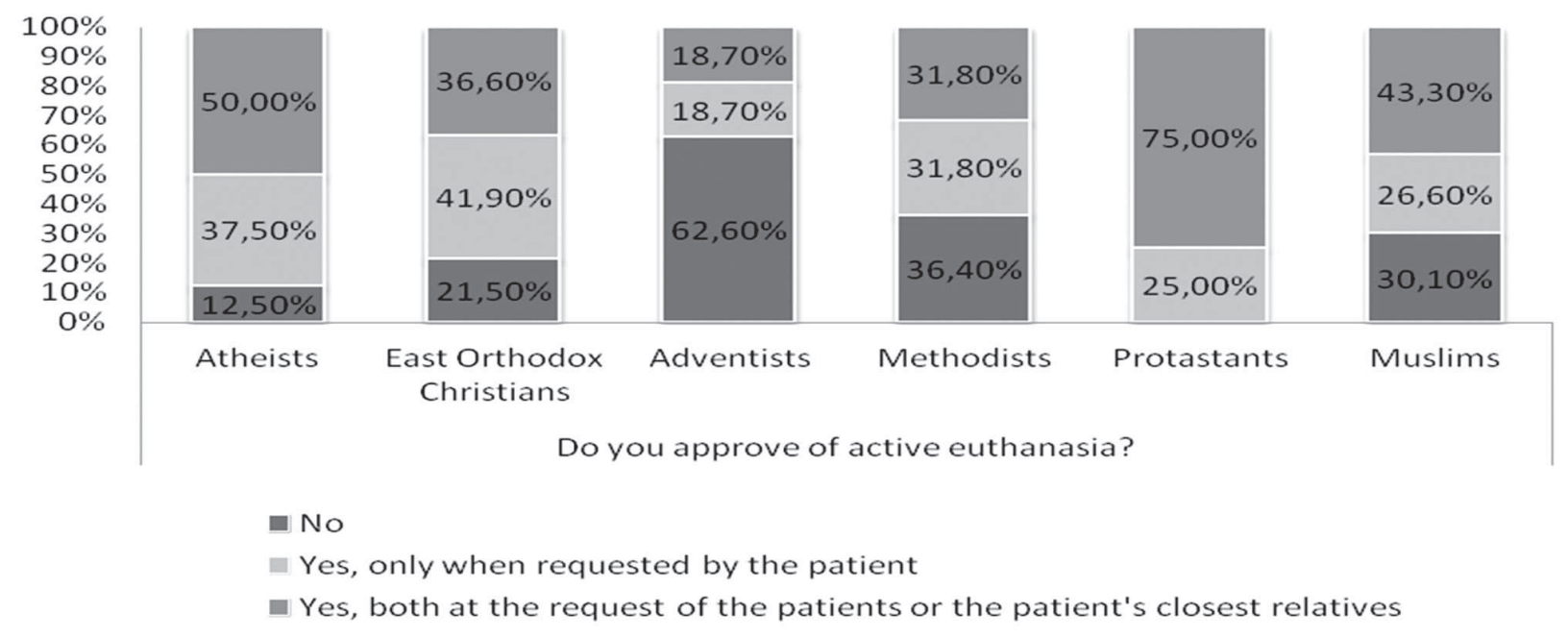

Fig. 3. Relationship between religious affiliation and approval of active euthanasia 
Paraskeva Mancheva, Albena Kerekovska, Valentina Madjova

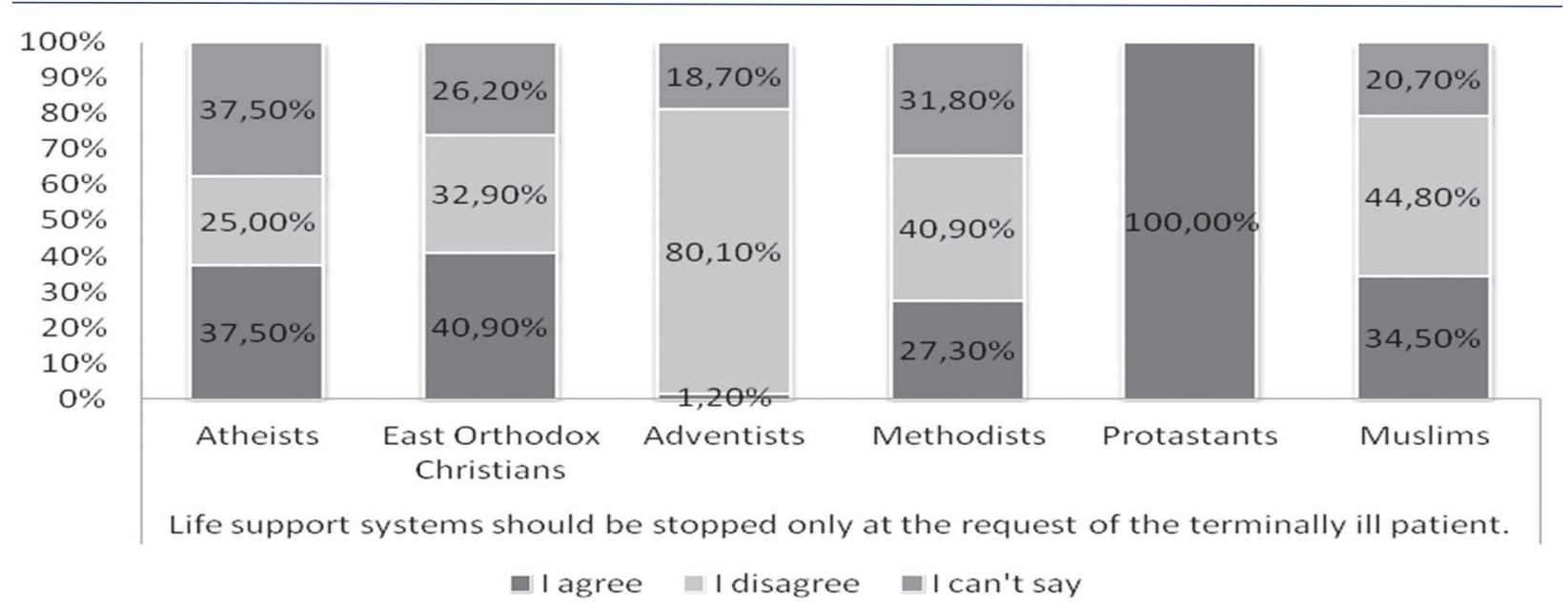

Fig. 4. Relationship between religious affiliation and passive euthanasia

the percentage of approval is significant among all of them (Fig. 3).

The analysis of respondents' opinion about passive euthanasia (Fig. 4) demonstrates a significant difference in the responses of the patients-followers of different religions $\left(\chi^{2}=21,69 ; \mathrm{p}<0,05\right)$. Protestants agree absolutely to stop life-support systems (100\%) while Adventists almost absolutely disagree (80,1\%).

With respect to a tendency to vote positively for legalizing active euthanasia, the group of Protestants presents with a high percentage of support (75\%). Adventists do not support it $(56, \%)$ followed by the Methodists (54,6\%) $\left(\chi^{2}=40,93 ; \mathrm{p}<0,01\right)$.

The behaviour of the different religious groups differs greatly with respect to their readiness to refuse treatment in case of a terminal status $\left(\chi^{2}=33,01\right.$; $\mathrm{p}<0,05)$. While $75 \%$ of Protestants are prone to refuse treatment in the event of suffering from an incurable terminal disease, Methodists demonstrate a change of opinion (54,5\%) together with Adventists who show a slight change towards agreement, too. Muslims are one group steady in their opinions concerning such important legal matter and $51,8 \%$ of them claim they will not refuse treatment irrespectively of the prognosis of their status.

The existence of some risks of abuse of legalized euthanasia is revealed, too. According to PP with PDWC, this may lead to certain pressures on the incurably and terminally ill patients to choose death in $67,5 \%$ of the cases $\left(\chi^{2}=32,96 ; p<0,001 ; r=-0,21\right.$; $\mathrm{p}<0,001)$. No conditions for legalizing the euthanasia in Bulgaria at presence are considered by $30,1 \%$ of the cases, and there exists a great risk of law abuse.

\section{DISCUSSION}

The results concerning the impact of demographic determinants on LC for euthanasia show that age is no determining factor in respect of its cognitive, psychological or behavioural element. Gender is important when it comes to informativeness and tendency to display certain behaviours, where women present with a more active behaviour to support euthanasia and its legalizing, while men tend to be more uncertain and undetermined in their opinions. The results about the significance of education level for LC determination indicate that higher educational status is a prerequisite for better informativeness about euthanasia-related issues. The occupation exerts an effect on the informativeness of PP with PDWC, too, as the retirees are less informed.

There is a substantial influence of the religious beliefs on LC formation with its three components, i.e. informativeness, attitude (acceptance, support) and readiness for certain behaviours concerning both passive and active euthanasia. Our results confirm the expectations of the importance of religious beliefs and affiliation for Bulgarians. In Bulgaria, the theological argument about the termination of human life is a traditionally insignificant factor in the formation of public opinions, ever since the introduction of Christianity in the country onwards when the Bulgarian rulers maintain a strong Caeserpapist line. 
Demographic determinants of legal consciousness for euthanasia legalization in patients with polymorbidity ...

On the other hand, the deviation from strict ecclesiastic canons are quite central to the life of medieval Bulgarians, as a result of which some movements such as Bogomilism, Danovism, sprung and pantheism and, ultimately, atheism are professed. Recent great democratic changes in Bulgarian society have expanded the possibilities for formation of religious affiliations among Bulgarians, which has led to the appearance of new movements within Christianity and they inevitably have found their place in our investigation.

\section{CONCLUSION}

With respect to demographic determinants of LC for euthanasia legalization in PP with PDWC, age does not exert any significant effect while gender, educational status and religious affiliation influence stronglier on informativeness, attitude (acceptance, support) and readiness for certain behaviours concerning both passive and active euthanasia.

Execution of the obligatory character of legal regulations is possible if these regulations are viewed by the prism of public LC. Its demographic determinants to legalize euthanasia in PP with PDWC exert a significant effect on its definition. Religious and sexual affiliation, education level and employment predetermine this large social group's acceptance level of a future statute law about euthanasia in the country. Our results prove the necessity of a preliminary investigation of LC of target social groups prior to execution of legal changes concerning certain socially important issues like euthanasia.

\section{REFERENCES}

1. Alexandrova, S. Medical ethics. Medical University of Pleven, 2007 (in Bulgarian).

2. Bamgbose, O. Euthanasia: another face of murder.Int. J. Offender Ther. Comp. Criminol., 48, 2004, No 1, 111-121.

3. Beauchamp, T., J. Childress. Principles of biomedical ethics. $3^{\text {rd }}$ ed. New York, Oxford University Press, 1989.

4. Council of Europe. Explanatory report to the Convention for the protection of human rights and dignity of the human being with regard to the applications of biology and medicine: Convention on human rights and biomedicine. Lisbon, Directorate of Legal Affairs, 1997.
5. Hadzhiyski, I., E., Ivanov, M., Hadzhiyska. Style of living and spirit of the Bulgarian nation. Vol. 1. Sofia, East-West, 2002-2003 (in Bulgarian).

6. Kornesov, L. Low of the euthanasia (Bill). Sofia, 27.VI.2011 (in Bulgarian).

7. Lisaev, P. Deontological and legal queries in the Medical Practice. Sofia, Foton, 2008, 137-150 (in Bulgarian).

8. Mancheva, P., A. Zabounov, M. Delijski. The polymorbid and permanently disabled patients in the general practice - quality of life assessment.- In: First Congress of General Medicine with International Participation. Varna, 3-6.XI. 2005. Book of abstracts, 42-43 (in Bulgarian).

9. Mancheva, P., A. Zabounov, V. Madjova, S. Hristova. Use of WHOQOL-BREF for polymorbid patients quality of life assessment in general practice.- In: First Congress of the Association of Doctors GP/FM in South-East Europe. Ohrid, 15 18.VI.2006. Book of abstracts, p. 154.

10. Materstvedt, L. J. Palliative care on the 'slippery slope' towards euthanasia?- Palliat. Med., 17, 2003, No 5, 387-392.

11. Molina, A., D. Rodríguez-Arias, S. J. Youngner. Should individuals choose their definition of death?- J. Med. Ethics, 34, 2008, No 9, 688-689.

12. Naumova, S. Legal conscience and legally relevant behaviour (law-sociological analysis).- Pravna misyl, 1986, No 3, 14-27 (in Bulgarian).

13. Naumova, S. Sociology of law. Sofia, Jurist's press, 2000 (in Bulgarian)

14. Naumova, S. Basic points of theory and sociology in the legislatives process.- Alternative, 7-8, 2001, No 1, 83-86 (in Bulgarian).

15. Parsons, T., G. Patt. Higher education and changing socialization.- In: Aging and society. Vol. 3. A sociology of age stratification. New York, Russell Sage Foundation, 1972.

16. Wasserman, J., J. M. Clair, F. J. Ritchey. A scale to assess attitudes toward euthanasia.- Omega (Westport), 51, 2005, No 3, 229-237. 